\title{
Twin pregnancy in each half of a didelphys uterus with delayed delivery and review of literature
}

\author{
Galya Levy, Nicolas Mottet, Marianne Fourel, Anne-Sarah Tholozan, Astrid Eckman, Rajeev Ramanah, and \\ Didier Riethmuller*
}

Department of Obstetrics and Gynecology, Besancon University Medical Centre, 3 Fleming Boulevard, 25000 Besancon, France

*Corresponding author's e-mail address: didier.riethmuller@univ-fcomte.fr

Published online: 26 March 2015 (version 1)

Cite as: G. Levy et al., ScienceOpen Research 2015 (DOI: 10.14293/S2199-1006.1.SOR-MED.ASNJHF.v1)

Reviewing status: Please note that this article is under continuous review. For the current reviewing status and the latest referee's comments please click here or scan the QR code at the end of this article.

\section{Primary Discipline Medicine}

Keywords: Didelphys uterus, Uterine malformation, Delayed delivery, Twin pregnancy, Female genital tract anomalies, Mullerian ducts

\begin{abstract}
Didelphys uterus results from an incomplete fusion of mullerian ducts and corresponds to the class III of mullerian abnormalities of the American Fertility Society. We describe the case of a spontaneous twin pregnancy developed in each cavity of a didelphys uterus. At 29 weeks of gestation and 6 days, the patient had preterm rupture of membranes in the right horn. She went into spontaneous labor and delivered vaginally the first "right" twin. Delivery was complicated with post-partum hemorrhage on uterine atonia treated with a Bakri balloon. She was tocolyzed to pursue the fetal lung maturity of the second twin. She had a rupture of the second membranes at 30 weeks and 3 days and had a preterm vaginal delivery at 32 weeks and 1 day of the second twin. Twin pregnancy in both horns of a uterus is extremely rare, about 1 in 1,000,000. Pregnancies on congenital abnormalities of the paramesonephric duct present frequently poor obstetrical outcomes and many complications. There are no guidelines about the follow-up of these high-risk patients or the mode of delivery.
\end{abstract}

\section{INTRODUCTION}

Didelphys uterus results from a complete failure of fusion of the two mullerian ducts in the female genital tract formation during the embryonic development. There is then two hemiuterus, each one with a uterine cavity, two cervices, and a vaginal septum. Twin pregnancies with a fetus in each cavity are extremely rare, approximately 1 in 1,000,000. We describe the case of a spontaneous twin pregnancy developed in each cavity of a didelphys uterus, with a premature vaginal delivery, and a delayed interval delivery of 16 days between the two twins.

\section{CASE}

The 26-year-old woman, gravida 2, para 0 has a bicornis bicollis uterus with a vaginal septum and initially an imperforated obstructed hemivagina on the right side which was diagnosed at the age of 14 following chronic pelvic pain. She had a vaginal septum resection at the age of 25 .

Diagnosis of an evolutive dichorionic diamniotic twin pregnancy with a fetus in each horn of the uterus was made on ultrasound at 8-week gestation (Figure 1). By convention, we named TA the fetus in the right horn, and TB the fetus in the left horn. This situation being of high risk of premature delivery, the patient was monthly followed by a clinical and sonographic evaluation. At 25 weeks, fetal lung maturation was undertaken by an injection of $12 \mathrm{mg}$ of betamethasone repeated 24 hours later.

She had a premature rupture of the membranes on TA at 29 weeks and 6 days.

On digital cervical examination the right cervix was posterior, short, soft, admitting one finger, and the right fetus cephalic presentation was high and mobile (Bishop score $=3$ ). The left cervix was the same as the right one. Speculum examination

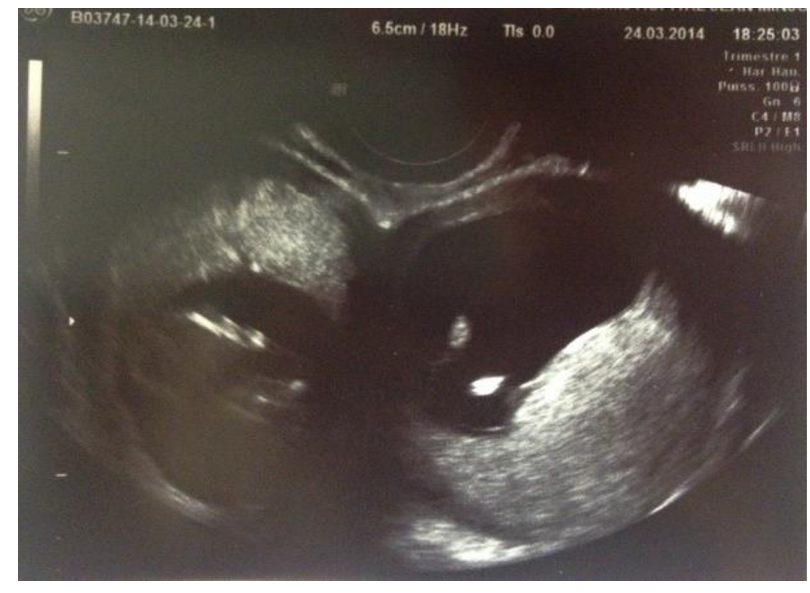

Figure 1. Ultrasound at eight gestational weeks. 
showed clear fluid going out the right cervix. Fetal heart rate of both fetus was normal. Biological parameters were normal without inflammation. Infection was searched with a urine and vaginal secretions examination. No tocolysis was made. The patient had antimicrobial prophylaxis by $1 \mathrm{~g}$ of ceftriaxone and a second cure of betamethasone. Labor started spontaneously the same day and ended with the spontaneous vaginal delivery of TA on vertex presentation, a boy weighing $1690 \mathrm{~g}$, who was transferred to pediatric intensive care unit due to respiratory distress. After the placenta's delivery which was complete, she presented a primary post-partum hemorrhage evaluated at $1550 \mathrm{cc}$ for which she had a right uterine revision, an inspection of the vagina, cervix, and perineum, and finally bleeding was stopped by a Bakri balloon inflated up to $300 \mathrm{cc}$. The latter was removed the day after. After verification of TB's good vitality and the mother's haemodynamic stability, it was decided to do tocolysis by atosiban for 48 hours. Urine and vaginal analysis was positive for Enterobacter cloacae and the patient was treated by cefepime (1 $\mathrm{g}$ twice a day intravenous for 8 days).

During the hospital stay, the patient had transfusion of four packs of red blood cells because of an anemia at $9 \mathrm{~g} / \mathrm{dL}$ and had two intravenous iron injections. Later, she had a preterm rupture of the membranes on TB at 30 weeks and 3 days. At 32 weeks and 1 day, labor started spontaneously and she had a vaginal delivery assisted by spatulas of a boy born in vertex presentation, weighing $2040 \mathrm{~g}$ transferred to neonatal care. The post-partum was uneventful and the patient was discharged on the fourth day post-partum.
Both children's evolution was favorable, and they went home respectively at 42 and 31 days post-partum.

\section{DISCUSSION}

Didelphys uterus corresponds to the class III of mullerian abnormalities from the American Fertility Society classification from 1988 [1] (Figure 2). It results from a complete failure of fusion on the median line of the two paramesonephric ducts or mullerian ducts during the embryonic development. It is frequently associated with an imperforated obstructed hemivagina on the side of a renal anomaly. The incidence of all those abnormalities is around $4.3 \%$ in the general population, and didelphys uterus represents $8.4 \%$ of them [2].

These female genital tract anomalies do not seem to be associated with a lower fertility [3] (except for agenesis) but generate poor obstetrical outcomes. Thus, in a review of literature, Grimbizis [2] showed for uterus didelphys a spontaneous abortion rate of $32.9 \%$, a premature delivery rate of $28.9 \%$, a term delivery rate of $36.2 \%$, and finally a live birth rate around $56.6 \%$. In addition to these complications, there is a higher rate of malpresentation, placental abruption and retained placenta, intrauterine growth restriction, operative delivery [4]. These complications are explained by three mechanisms: decreased muscle mass, abnormal uterine blood flow, and cervical insufficiency.

Twin pregnancies with a fetus in each cavity of a didelphys uterus are extremely rare, approximately 1 in 1,000,000 [5]. We sorted out in the literature 8 twin pregnancy cases which occurred on bicornis unicornis uterus with a fetus in each

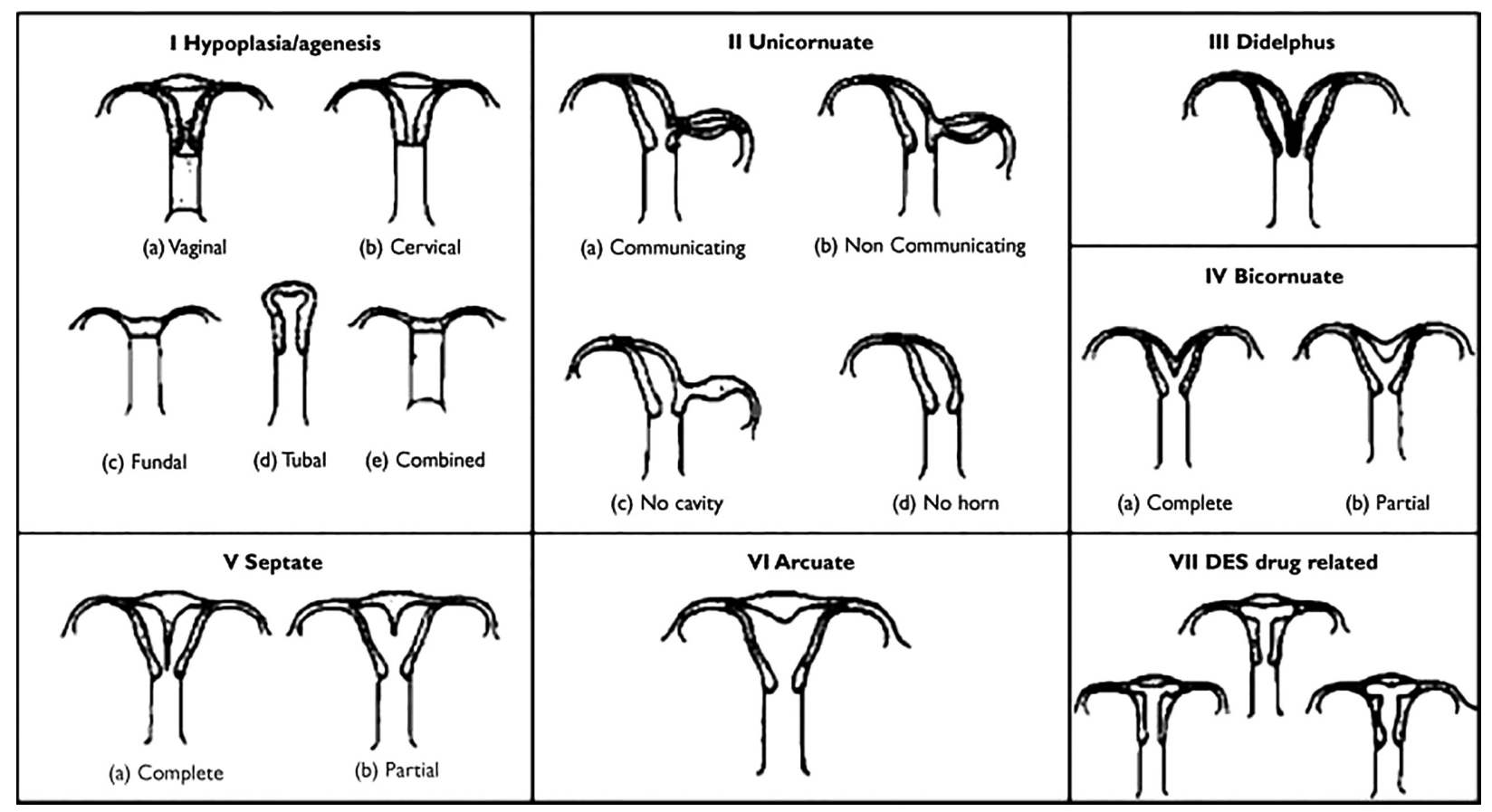

Figure 2. Mullerian anomalies classification by the AFS 1988 [1]. 
Table 1. Literature review of simultaneous twin pregnancies in each cavity of a didelphys uterus with favorable outcomes.

\begin{tabular}{|c|c|c|c|c|c|c|c|}
\hline Author, date & $\begin{array}{l}\text { Circumstances } \\
\text { of discovery }\end{array}$ & $\begin{array}{c}\text { Spontaneous } \\
\text { or induced } \\
\text { pregnancy }\end{array}$ & $\begin{array}{c}\text { GA J1 } \\
\text { (WG+ days) }\end{array}$ & $\begin{array}{c}\text { GA J2 } \\
\text { (WG+ days) }\end{array}$ & $\begin{array}{l}\text { Delays } \\
\text { (days) }\end{array}$ & Delivery mode & Remarks \\
\hline $\begin{array}{l}\text { Hochner-Celnikier et al. } \\
\text { (1983)[6] }\end{array}$ & HSG, infertility & Induced & 38 & 38 & 0 & Cesarean & Breech T1 \\
\hline Kekkonen et al. (1991)[8] & First pregnancy & Spontaneous & 38 & 38 & 0 & Cesarean & \\
\hline Bongain et al. (1994)[9] & & Spontaneous & 34 & 34 & 0 & Cesarean & \\
\hline Ahmad et al. (2000)[10] & & Spontaneous & 31 & 31 & 0 & Cesarean & $\begin{array}{l}\text { Failed labor induction } \\
\text { for PRM }\end{array}$ \\
\hline Tyagi et al. (2001)[5] & & Spontaneous & 33 & $33+5$ & 5 & Vaginal & \\
\hline Nohara et al. (2003)[7] & HSG & Induite & 25 & 35 & 66 & Cesarean T1 Vaginal T2 & \\
\hline Garg et al. (2010)[11] & $\begin{array}{l}\text { Clinical diagnosis } \\
\text { during pregnancy }\end{array}$ & Spontaneous & 37 & 37 & 0 & Cesarean & \\
\hline Maki et al. (2013)[12] & Previous pregnancy & Spontaneous & $37+6$ & $37+6$ & 0 & Vaginal T1 Cesarean T2 & $\begin{array}{l}\text { Cesarean for fetal rate } \\
\text { abnormalities }\end{array}$ \\
\hline Our case & Hematocolpos & Spontaneous & $29+6$ & $32+1$ & 16 & Vaginal & \\
\hline
\end{tabular}

GA, gestational age; HSG, hysterosalpingography; WG, weeks of gestation; PRM, premature rupture of membranes.

cavity, whose outcomes were favorable for both twins (Table 1). In two cases pregnancy was induced, one by simple induction of ovulation [6], the other by induction combined with transcervical insemination in each uterine cavity [7]. There was a simultaneous cesarean section on both hemi-uterus in five cases [6, 8-11], one vaginal delayed delivery of 5 days [5], one case with a cesarean section on the first twin at 25 weeks, followed by a vaginal delivery on the second twin at 35 weeks [7], and finally a case with a vaginal delivery for the first twin then a cesarean section for the second because of fetal heart rate anomalies [12].

Spontaneous labor of only one hemi-uterus and delayed delivery of the two twins corroborate with the hypothesis that the initiation of labor is a local phenomenon, with a role of the fetus and placenta, and not a general phenomenon [5]. The pregnancy continuation after the birth of the first twin in the case of a double uterus allows the delayed delivery of the second twin and so increases his chances by reducing the impact of prematurity.

In our case, the 2-week interval allowed us to do a complete lung maturation for the second twin and come through the very premature birth period.

\section{CONCLUSION}

There are neither recommendations for monitoring modalities nor for the delivery mode.

Monthly follow-up, similar to every dichorionic diamniotic twin pregnancy, seems to be correct so as to assess fetal growth and to screen for complications. Because of the high risk of prematurity, systematic lung maturation by a corticoid injection appears to be necessary once the vitality is reached. While the first reports seemed to promote cesarean sections, vaginal deliveries are nowadays increasingly practiced because of their lower maternal complication rate. Pregnancy conservation after first twin delivery in that particular situation allows delayed delivery of the second twin and facilitates its management by decreasing the impact of prematurity.

\section{REFERENCES}

[1] Buttram VC, Gomel V, Siegler A, DeCherney A, Gibbons W, March C. The American Fertility Society classifications of adnexal adhesions, distal tubal occlusion, tubal occlusion secondary to tubal ligation, tubal pregnancies, Mullerian anomalies and intrauterine adhesions. Fertil Steril. 1988;49(6):944-55.

[2] Grimbizis GF. Clinical implications of uterine malformations and hysteroscopic treatment results. Hum Reprod Update. 2001;7(2): 161-74.

[3] Raga F, Bauset C, Remohi J, Bonilla-Musoles F, Simon C, Pellicer A. Reproductive impact of congenital Mullerian anomalies. Hum Reprod. 1997;12(10):2277-81.

[4] Reichman DE, Laufer MR. Congenital uterine anomalies affecting reproduction. Best Pract Res Clin Obstet Gynaecol. 2010;24(2): 193-208.

[5] Tyagi A, Minocha B, Prateek S. Delayed delivery of second twin in uterus didelphys. Int J Gynecol Obstet. 2001;73(3): 259-60.

[6] Hochner-Celnikier D, Yagel S, Beller U, Milwidsky A. Simultaneous pregnancy in each cavity of a double uterus. A case report. Int J Gynecol Obstet. 1983;21(1):51-3.

[7] Nohara M, Nakayama M, Masamoto H, Nakazato K, Sakumoto K, Kanazawa K. Twin pregnancy in each half of a uterus didelphys with a delivery interval of 66 days. Brit J Obstet Gynaecol. 2003; 110(3):331-2.

[8] Kekkonen R, Nuutila M, Laatikainen T. Twin pregnancy with a fetus in each half of a uterus didelphys. 2009. Acta Obstet Gynecol Scand. 1991;70(4-5):373-4.

[9] Bongain A, Constantopoulos P, Castillon JM, Ibghi W, Isnard V, Gillet JY. Grossesse simultanée dans chaque cavité d'un utérus bicorne bicervical avec vagin double. Rev Fr Gynecol Obstet. 1994;89(1):32-5.

[10] Ahmad FK, Sherman SJ, Hagglund KH. Twin gestation in a woman with a uterus didelphys. A case report. J Reprod Med. 2000;45(4):357-9.

[11] Garg R, Kwatra A, Bangal V. Rare case of uterus didelphys with full term pregnancy in each horn. Pravara Med Rev. 2010;2(4): 22-4.

[12] Maki Y, Furukawa S. Independent uterine contractions in simultaneous twin pregnancy in each horn of the uterus didelphys. J Obstet Gynaecol Res. 2014;40(3):836-9. 


\section{COMPETING INTERESTS}

The authors declare no competing interests.

\section{PUBLISHING NOTES}

(C) 2015 Levy et al. This work has been published open access under Creative Commons Attribution License CC BY 4.0, which permits unrestricted use, distribution, and reproduction in any medium, provided the original work is properly cited. Conditions, terms of use and publishing policy can be found at www.scienceopen.com.
Please note that this article may not have been peer reviewed yet and is under continuous post-publication peer review. For the current reviewing status please click here or scan the QR code on the right.

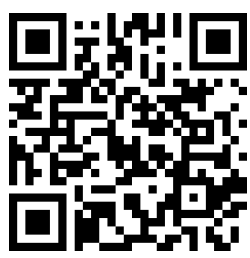

